\title{
Analysis of the Power System from an Electron Beam Accelerator and the Correlation with the Theoretical Dosimetry for Radiation Processing
}

\author{
Samir Luiz Somessari ${ }^{*}$, Elizabeth S. Ribeiro Somessari, Carlos Gaia da Silveira and Wilson Aparecido Parejo \\ Calvo \\ Radiation Technology Centre, Nuclear and Energy Research Institute, National Nuclear Energy Commission (IPEN-CNEN/SP), Sao \\ Paulo, 05508-000, Brazil
}

\begin{abstract}
Dynamitron DC1500/25/04 type EBA (Electron beam accelerator), model JOB 188, was manufactured by IBA Industrial (Radiation Dynamics, Inc.) and installed at IPEN-CNEN/SP, in 1978. The technical specifications of the EBA are: energy 0.5 to $1.5 \mathrm{MeV}$; beam current: 0.3 to $25.0 \mathrm{~mA}$; beam scanning: 60 to $120 \mathrm{~cm}$; beam width: $25.4 \mathrm{~mm}$ and frequency: $100 \mathrm{~Hz}$. Nowadays, this accelerator has been used for innumerable applications, such as: For sterilization of medical, pharmaceutical and biological products, treatment of industrial and domestic effluents and sludge, preservation and disinfestations of foods and agricultural products. Other important application are lignocellulosic material irradiation as a pre-treatment to produce ethanol bio-fuel, decontamination of pesticide packing, solid residues remediation, organic compounds removal from wastewater, treatment of effluent from petroleum production units, crosslinking of foams, wires and electric cables. Electron accelerator JOB 188 is, also, very important composite and nanocomposite materials and carbon fibers irradiation, irradiated grafting ion-exchange membranes for fuel cells application, natural polymers and multilayer packages irradiation and biodegradable blends production. The energy of the electron beam is calculated as a function of the current in the accelerator high-voltage divisor, taking into account the thickness and density of the material to be irradiated. This energy is calculated considering the electron through the entire material and the distance from the titanium foil window, so that the absorbed doses at the points of entrance and exit are equivalent on the material. The dose is directly proportional to the beam current and the exposure time of the material under the electron beam and inversely proportional to the scan width. The aim of this paper is to analyze the power system parameters of the EBA Dynamitron DC1500/25/04, such as, voltage and RMS (Root-mean-square) current in the oscillator system, high voltage generator and waveform. For this purpose software developed in the Radiation Technology Center at IPEN/CNEN-SP to simulate the energy efficiency of this industrial accelerator. Finally, it is also targeted to compare theoretical dosimetry using parameters of energy and beam current with data from the accelerator power system. This knowledge and technology will be very useful and essential for the control system upgrade of EBA, mainly Dynamitron DC1500/25/04 taking into consideration that radiation processing technology for industrial and environmental applications has been developed and used worldwide.
\end{abstract}

Key words: Electron beam accelerator, industrial dosimetry, radiation processing, accelerator power system, Dynamitron DC1500/25/04 accelerator.

\section{Introduction}

Electron beam processing is an important technology that the IAEA (International Atomic Energy Agency) supports and promotes, having several programs to facilitate its use in developing

\footnotetext{
*Corresponding author: Samir Luiz Somessari, electronic engineer, research fields: automation systems, industrial electronic systems and electron beam accelerators.
}

Member States. This technology is used in diverse industries to enhance the physical and chemical properties of materials and to reduce undesirable contaminants, such as pathogens or toxic by-products [1].

The industrial uses of EBA (Electron beam accelerator) started in the late 1950's, with the crosslinking of polyethylene wire insulation. Nowadays, the number of EBA in use for various 
radiation processing applications exceeds 1,500 radioactive facilities. These accelerators are used mainly in plastics, automotive field, wire and electric cables, semiconductors, health care, aerospace and environmental industries, as well as, numerous research and development facilities around the world $[2,3]$.

Crosslinking provides significant commercial benefits to wire and cable insulation. Ionizing energy, as provided by an accelerated EB (Electron beam), is an efficient means of crosslinking the polymers that are used for wire and cable jacketing. In this process, chemical bonds are formed between polymer molecules to produce a three-dimensional insoluble network. EB processing is faster, more controllable and more economical than thermal and/or chemical crosslinking, when used in the production of insulated wires and cables [4].

The most important specification for any irradiation process is the absorbed dose. The quantitative effects of the process are related to this factor. Absorbed dose is proportional to the ionizing energy delivered per unit mass of material. The international unit of dose is the Gray (Gy), which is defined as the absorption of one joule per kilogram $(\mathrm{J} / \mathrm{kg})$. A more convenient unit for most radiation processing applications is the kilogray $(\mathrm{kJ} / \mathrm{kg}$ or $\mathrm{J} / \mathrm{g})$ [5].

The objective is to analyze the power system parameters of the EBA Dynamitron DC1500/25/04, such as, voltage and RMS (Root-mean-square) current in the oscillator system, high voltage generator and waveform, using software developed to simulate the energy efficiency of this industrial accelerator. It is also targeted to compare theoretical dosimetry using parameters of energy and beam current with data from the accelerator power system.

The basic operation of the accelerator electron DC1500/25/4- JOB188 oscillator panel turns 440 Volts AC - $60 \mathrm{~Hz}$, for up to 10,000 Volts, with a frequency of $100 \mathrm{kHz}$, connected to the pressure vessel. In the pressure vessel, there is a resonant electronic circuit, which takes up a voltage 10.000 Volts $/ 100 \mathrm{kHz}$ generated by the oscillator panel and processed in an order of 1,500 kV DC. The voltage inside the pressure vessel is very high: to avoid sparks or short circuit inside the pressure vessel, an insulating gas $\left(\mathrm{SF}_{6}\right.$ sulfur hexafluoride) is used; to measure the high voltage in the pressure vessel, a shunt (resistors) is used, indicating an electrical current, called HVD (High voltage divider). The tension generated in the pressure vessel of up to $1,500,000$ Volts DC polarizes the beam tube assembly, where the penetration energy of the beam electrons was determined, through the shunt (resistors); the bias current measurement of the tube is called BTD (Beam tube divider); the LVR is the sum of electric currents, which involve the tube beam current (BTD), the current of high voltage (HVD) and other currents. Polarizing the tungsten filament, and by heating, a beam current of the electron accelerator is generated. The scan system and optics contain some coils that are polarized with a certain voltage/frequency, determined by the frequency scanning [6-9].

1.1 Absorbed Dose versus Electron Beam Current and Area Throughput Rate

Dose is calculated by Eq. (1):

$$
\mathrm{D}=\mathrm{E} / \mathrm{M}
$$

In which,

$\mathrm{D}=$ Dose $(\mathrm{kGy})$;

$\mathrm{E}=$ Absorbed energy $(\mathrm{kJ})$;

$\mathrm{M}=$ Mass $(\mathrm{kg})$.

Additionally,

Absorbed energy $(\mathrm{kJ})=$ Beam power, $\mathrm{P}(\mathrm{kW})$ * Treatment time, $\mathrm{T}(\mathrm{s})$;

Beam power, $\mathrm{P}(\mathrm{kW})=$ Electron energy, $\mathrm{E}(\mathrm{MeV})$ * Beam current, I (mA);

Electron energy, $\mathrm{E}(\mathrm{MeV})=\mathrm{D}(\mathrm{e})\left(\mathrm{MeV} \cdot \mathrm{cm}^{2} / \mathrm{g}\right) * \mathrm{Z}$ $\left(\mathrm{g} / \mathrm{cm}^{2}\right)$;

$\mathrm{D}(\mathrm{e})=$ Energy deposition per unit area density per incident electron;

$\mathrm{Z}=$ Thickness $(\mathrm{cm}) *$ Volume density $\left(\mathrm{g} / \mathrm{cm}^{3}\right)$;

$\mathrm{Z}=$ Mass, $\mathrm{M}(\mathrm{g}) /$ Area, $\mathrm{A}\left(\mathrm{cm}^{2}\right)$ or Area density $\left(\mathrm{g} / \mathrm{cm}^{2}\right)$; 
Mass, $\mathrm{M}(\mathrm{g})=\mathrm{Z}\left(\mathrm{g} / \mathrm{cm}^{2}\right) *$ Area $\mathrm{A}\left(\mathrm{cm}^{2}\right)$.

Then,

$$
\begin{aligned}
& \mathrm{D}(\mathrm{kGy})=\mathrm{P}(\mathrm{kW}) * \mathrm{~T}(\mathrm{~s}) / \mathrm{M}(\mathrm{kg}) ; \\
& \mathrm{D}(\mathrm{kGy})=\mathrm{E}(\mathrm{MeV}) * \mathrm{I}(\mathrm{mA}) * \mathrm{~T}(\mathrm{~s}) / \mathrm{M}(\mathrm{kg}) ; \\
& \mathrm{D}(\mathrm{kGy})=\mathrm{D}(\mathrm{e})(\mathrm{MeV} \mathrm{cm} / \mathrm{g}) * \mathrm{Z}\left(\mathrm{g} / \mathrm{cm}^{2}\right) * \mathrm{I}(\mathrm{mA}) *
\end{aligned}
$$

$\mathrm{T}(\mathrm{s}) / \mathrm{M}(\mathrm{kg})$;

$$
\begin{aligned}
& \mathrm{D}(\mathrm{kGy})=\mathrm{D}(\mathrm{e}) * \mathrm{Z} * \mathrm{I} * \mathrm{~T} /\left[\mathrm{Z} * \mathrm{~A}\left(\mathrm{~cm}^{2}\right) * 10^{-3}\right] ; \\
& \mathrm{D}(\mathrm{kGy})=\mathrm{D}(\mathrm{e}) * \mathrm{I} * \mathrm{~T} /\left[\mathrm{A}\left(\mathrm{m}^{2}\right) * 10\right] .
\end{aligned}
$$

Furthermore, dose at depth $\mathrm{z}$ in the irradiated material is calculated by Eq. (2).

$\mathrm{D}(\mathrm{z})=$ Dose at depth $\mathrm{z}$ in the irradiated material;

$\mathrm{D}(\mathrm{e}, \mathrm{z})=$ Electron energy deposition at depth $\mathrm{z}$ in the material;

$\mathrm{F}(\mathrm{i})=$ Fraction of emitted beam current intercepted by the material.

Then,

$$
\mathrm{D}(\mathrm{z})=\mathrm{D}(\mathrm{e}, \mathrm{z}) \cdot \mathrm{F}(\mathrm{i}) \cdot \mathrm{I} \cdot \mathrm{T} /(10 \mathrm{~A})
$$

or

$$
\mathrm{D}(\mathrm{z})=\mathrm{D}(\mathrm{e}, \mathrm{z}) \cdot \mathrm{F}(\mathrm{i}) \cdot \mathrm{I} /(10 \mathrm{~A} / \mathrm{T})
$$

\section{Methods, Materials and Testing}

\section{Procedures}

The curve of dose distribution with raised CTA (Cellulose triacetate) dosimeter (density, $\rho=1.32 \mathrm{~g} / \mathrm{cm}^{3}$ ) for EB energy of $1.5 \mathrm{MeV}$, from which the remaining curves were constructed in this study is shown in Fig. 1. In this curve, it was considered that the desired dose on the surface of the material and the dose distribution, in percentage, at this bulk area density function ( $\sigma=$ density against thickness $)$ in $\mathrm{g} / \mathrm{cm}^{2}$. The curve was prepared at the IPEN-CNEN/SP's Dosimetry Laboratory.

In Fig. 2, the power system schematic diagram of the EBA is shown, with its properties of voltage, current and other electrical parameters and measurement points, using scopemeter, multimeters and probes to specific current measures and voltage.

In Fig. 3, energy curves between LVR of the current return circuit voltage and power in the oscillator triode EBA system are shown. Curves of power determined in the oscillator panel show that the effectiveness of the EBA is $45.53 \%$. This means that beam energy of $15 \mathrm{~kW}$ should have a power triode of $32.94 \mathrm{~kW}$, in the oscillator panel.

In Fig. 4, curves of electron energies and high voltage in the pressure vessel of accelerator are shown. Curves ratio between high voltage and energy, and ratio between energy $(\mathrm{MeV})$ with HVD are also shown.

\subsection{Types and Forms of Irradiation Processes-Plan Materials}

The irradiation system for this type of material consists of convey or roller driven currents, which are placed on trays where the materials are distributed to

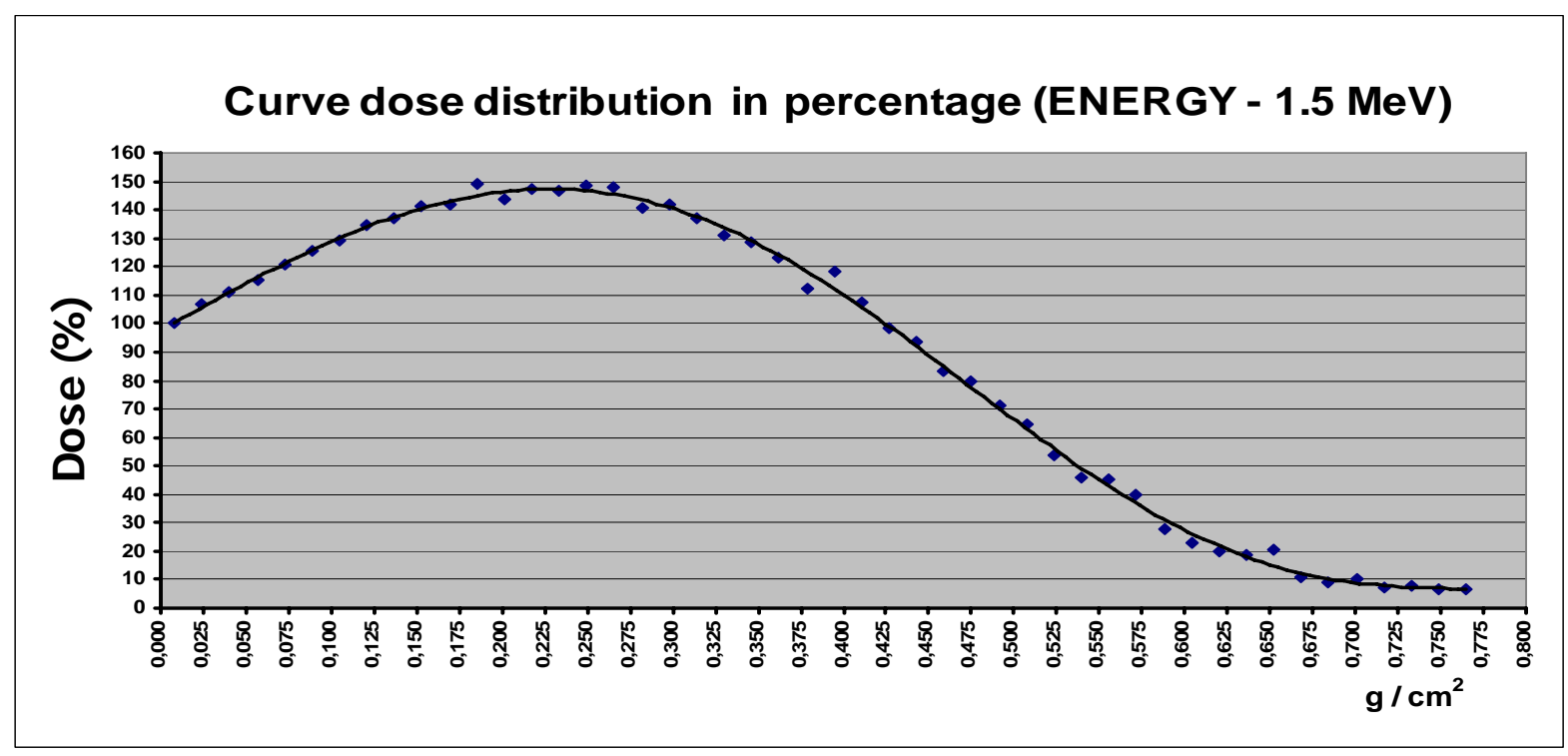

Fig. 1 Dose distribution with raised CTA dosimeter for EB energy of $1.5 \mathrm{MeV}$. 

Theoretical Dosimetry for Radiation Processing

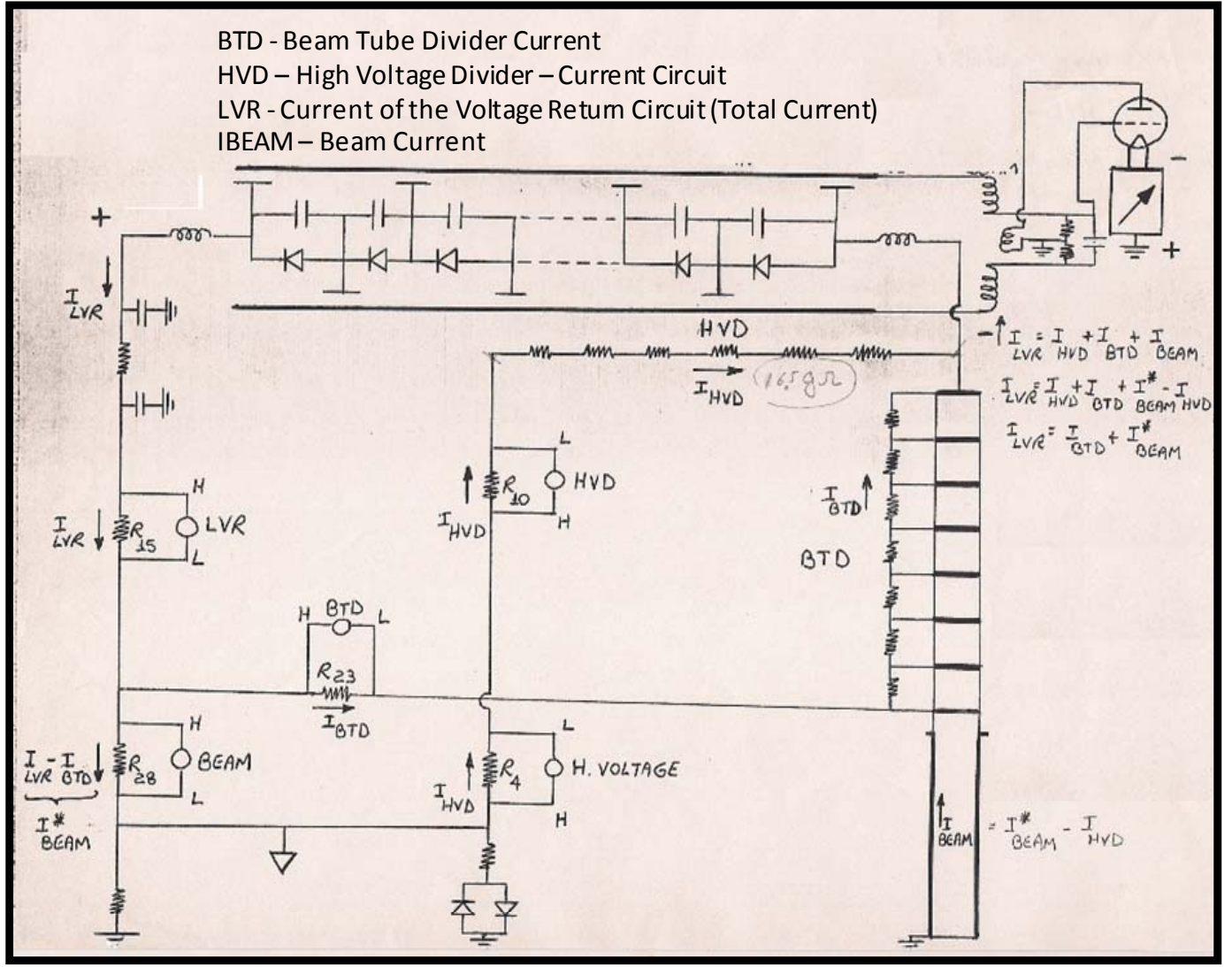

Fig. 2 Power system schematic diagram of the EBA.

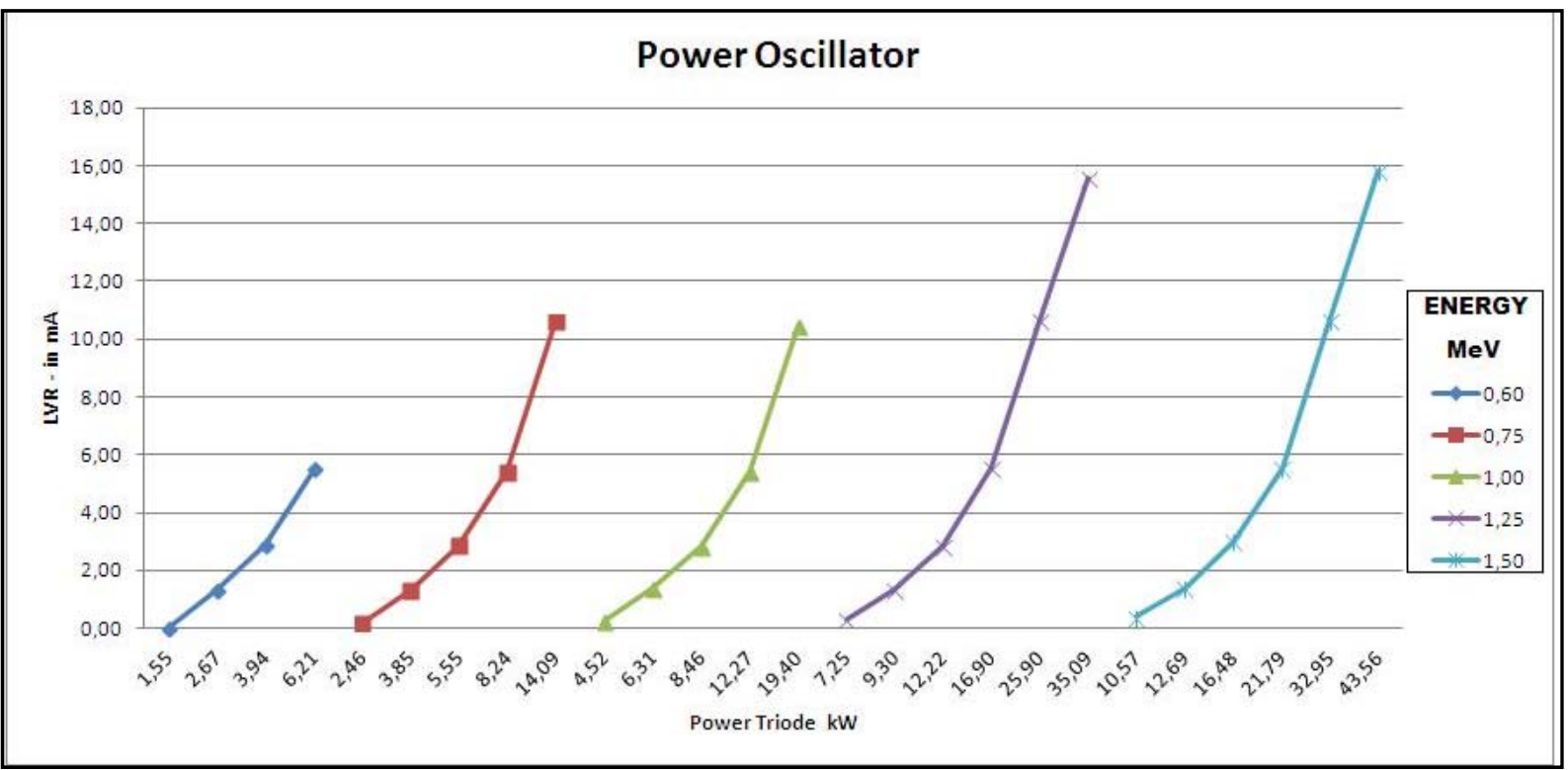

Fig. 3 Energy curves (MeV)of LVR current (mA) versus power triode (kW).

be irradiated. This conveyer is composed of two modules: one-way, which takes the tray with the material inside their radiation chamber (Fig. 5) to their radiator (electron accelerator) and another (that brings back) the tray out of their radiation chamber. After the tray with the material passes through the electron beam, it is transported by currents to the module return (back), again passing through the beam. 

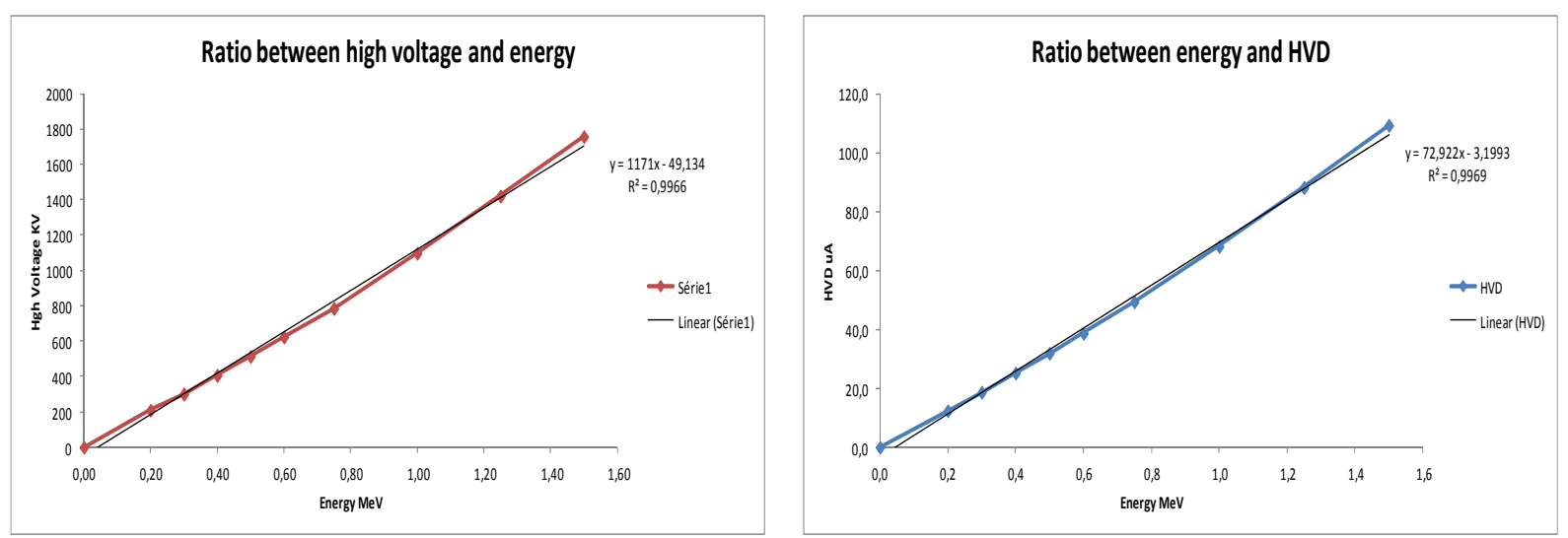

Fig. 4 Curves of high voltage $(\mathrm{kV})$ versus energy $(\mathrm{MeV})$ and HVD $(\mu \mathrm{A})$ versus energy $(\mathrm{MeV})$.

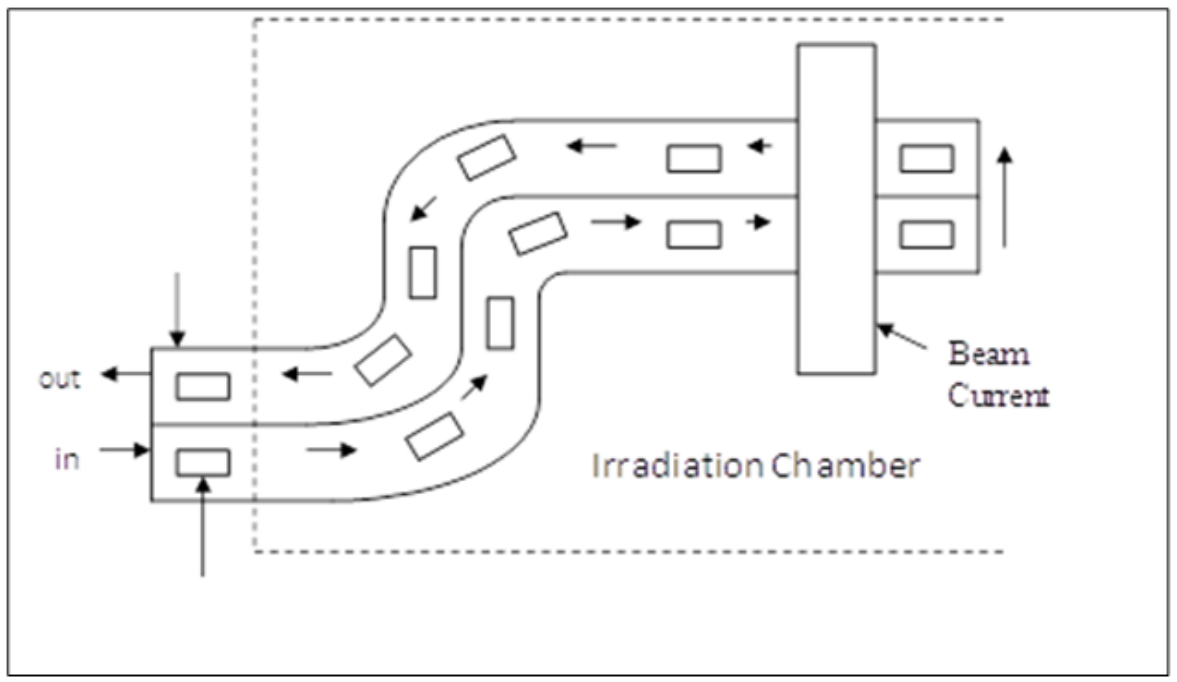

Fig. 5 Conveyer installed in their radiation chamber at IPEN-CNEN/SP.

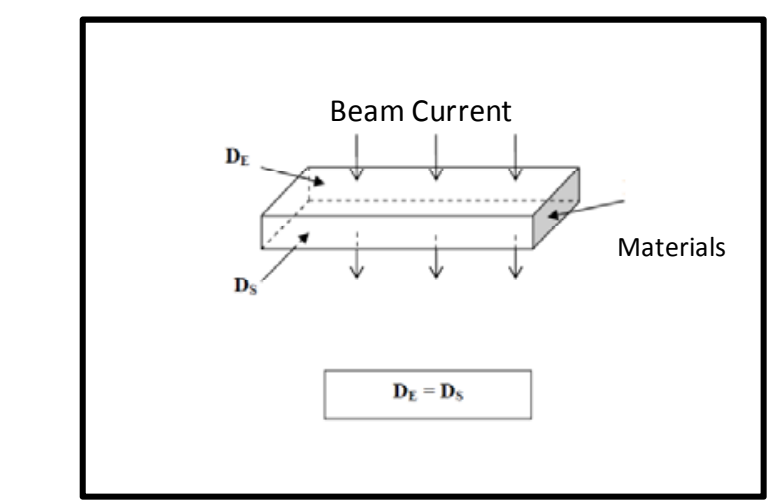

Fig. 6 Irradiation form I - plan material irradiation diagram.

Therefore, for each tray back on the conveyer (input and output tray of their radiation chamber), the material passes twice by the electron beam.

2.1.1 Irradiation form I - Plan Material

In this irradiation form I, the electron beam runs through the material so that the dose sat the point of input and output are equals (Fig. 6).

The curve of dose distribution (irradiation form I) is shown in Fig. 7, take into account the following irradiation parameters,

Energy (E): $1.5 \mathrm{MeV}$;

Beam current (I): $10 \mathrm{~mA}$;

Scanning beam: $100 \mathrm{~cm}$;

Material transport speed (v): $10 \mathrm{~m} / \mathrm{min}$;

Number of electron beam passes (P): 2 (1 turn on the treadmill);

Dose for pass (D/P): $6 \mathrm{kGy}$;

Total dose (TD): $12 \mathrm{kGy}$;

Dose rate: $40 \mathrm{kGy} / \mathrm{s}$;

Density $(\rho): 1 \mathrm{~g} / \mathrm{cm}^{3}$;

Thickness: $4.45 \mathrm{~mm}$. 

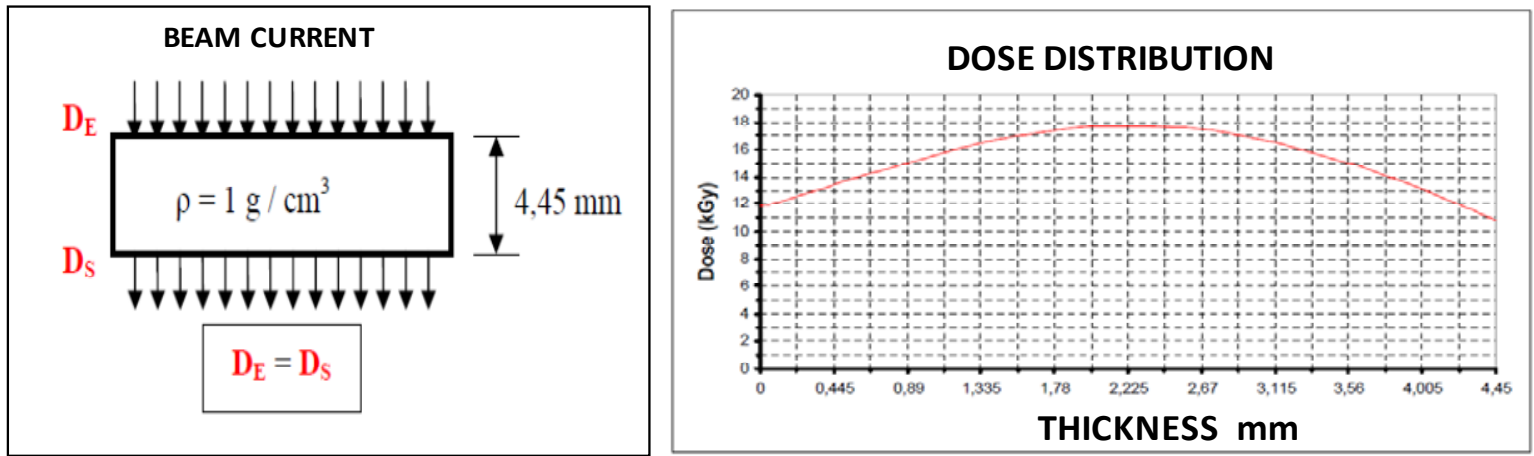

Fig. 7 Irradiation form I - plan material irradiation diagram and dose distribution curveas a function of the sample thickness (kGy/mm).

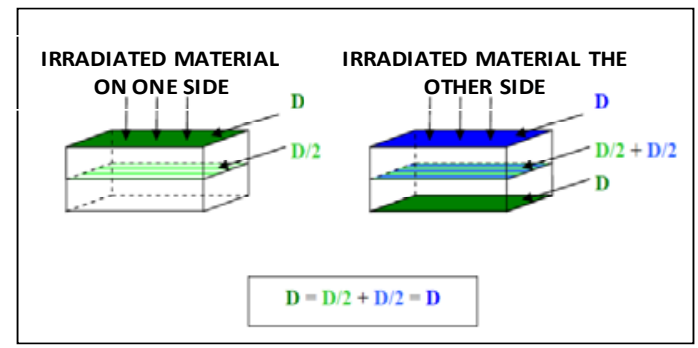

Fig. 8 Irradiation form II - plan material irradiation diagram.

Take into account the power beam of $15 \mathrm{~kW}$ and beam thickness of $25.4 \mathrm{~mm}(1$ "), dose in their radiated material is calculated by Eq. (3):

$$
\mathrm{D}(\mathrm{kGy})=15 \mathrm{~kW} \cdot \operatorname{Time}(\mathrm{s}) / \mathrm{M}(\mathrm{kg}) *
$$

*Application of Eq. (3) is not so evident, since a number of factors should be considered, such as the size and the shape of the object to calculate the area, volume and mass. The fraction of energy deposited on the material, by back scattering dispersion of the beam, can be calculated by means of Monte Carlo simulation [5].

\subsubsection{Irradiation form II - Plan Material}

In this irradiation form II, the electron beam cannot pass through the entire material. It is necessary to irradiate it on both sides, so that after being irradiated from both sides, the dose on the surfaces of the material and the medium are equals (Fig. 8).

The curve of dose distribution (irradiation form II) is shown in Fig. 9 take into account the following irradiation parameters:

Energy (E): $1.5 \mathrm{MeV}$;

Beam current (I): $10 \mathrm{~mA}$;
Scanning beam: $100 \mathrm{~cm}$;

Material transport speed (v): $10 \mathrm{~m} / \mathrm{min}$;

Number of electron beam passes (P): 2 (1 turn on the treadmill, on one side of the material) plus 2 ( 1 turn on the treadmill, on the other side of the material);

Dose for pass (D/P): $6 \mathrm{kGy}$;

Total dose (TD): $12 \mathrm{kGy}$;

Dose rate (D): $40 \mathrm{kGy} / \mathrm{s}$;

Density $(\rho): 1 \mathrm{~g} / \mathrm{cm}^{3}$;

Thickness: $11.3 \mathrm{~mm}$.

Take into account the power beam of $15 \mathrm{~kW}$ and beam thickness of $25.4 \mathrm{~mm}(1$ "), dose in their radiated material is calculated by Eq. (3).

\subsection{Irradiation of Wires and Electric Cables}

The irradiation system for wires and electric cables consists of two sets of pulleys, with 24 pulleys each, placed in parallel so that the electron beam is between them. The electric cable passing from a sheave of a pulley set for the other set is irradiated and, to make the contrary path, in the position diametrically opposite to the previous one, is again irradiated. This going and return of electric cable is called link.

\subsubsection{Irradiation form I - Wires and Electric Cables}

In this irradiation form I, the electric cable is fully irradiated in two positions (roundtrip), passing through the electron beam. Taking into account the internal diameter (wire diameter) and the outside diameter (overall cable diameter), the electron traverses across the tangent line to the conductor (greater extension 

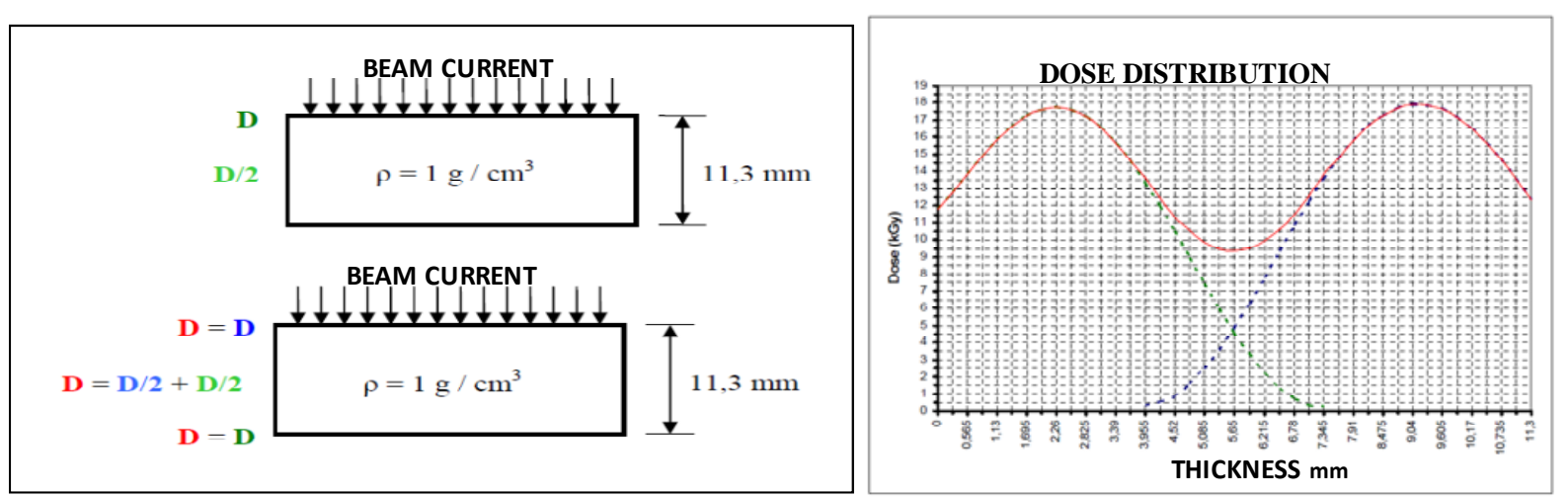

Fig. 9 Irradiation form II - plan material irradiation diagram and dose distribution curves as a function of the sample thickness (kGy/mm).

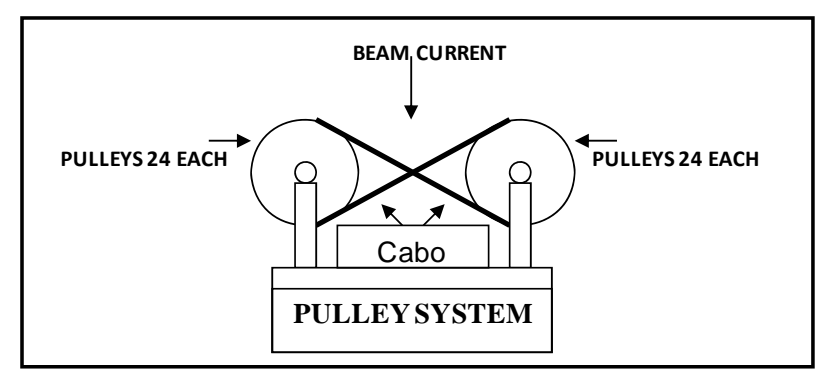

Fig. 10 Pulley system for wires and electric cables irradiation by electron beam.

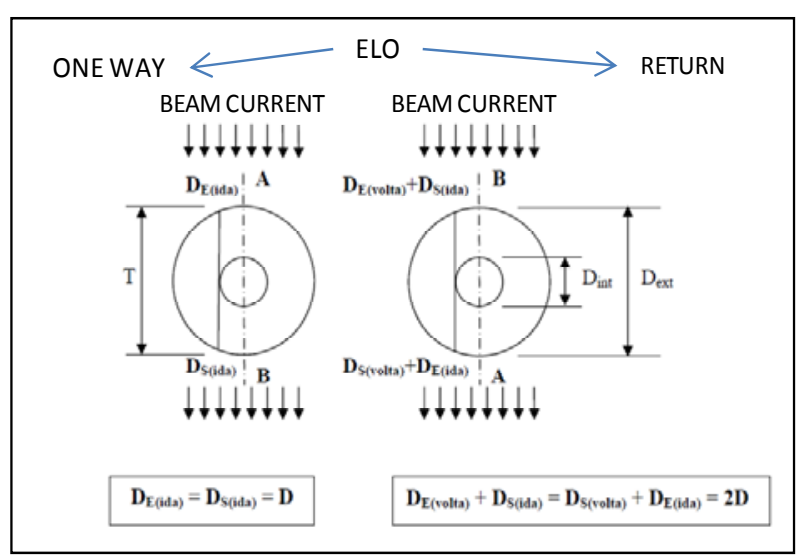

Fig. 11 Irradiation form I - wires and electric cables.

insulator), so that the dose at the points of input and output are equals (Fig. 11).

Examples of irradiation conditions of wires and electric cables in pulley system are shown in Fig. 12. The curve of dose distribution (irradiation form I) is shown in Fig. 13, take into account the following irradiation parameters:

Energy (E): $1.5 \mathrm{MeV}$;

Beam current (I): $10 \mathrm{~mA}$;

Scanning beam: $100 \mathrm{~cm}$;
Speed (v): $100 \mathrm{~m} / \mathrm{min}$;

Number of electron beam passes (P): 48 (24 links);

Total dose (TD): $28.8 \mathrm{kGy}$;

Dose rate (D):40 kGy/s;

Density of the insulating $(\rho): 1 \mathrm{~g} / \mathrm{cm}^{3}$;

Core (internal diameter): $1 \mathrm{~mm}$ (wire diameter);

Outside diameter: $4.56 \mathrm{~mm}$ (overall diameter of the electric cable);

Power beam: $15 \mathrm{~kW}$;

Beam thickness: $25.4 \mathrm{~mm}$ (1").

Take into account the power beam of $15 \mathrm{~kW}$ and beam thickness of $25.4 \mathrm{~mm}(1$ "), dose in their radiated material is calculated by Eq. (3).

2.2.2 Irradiation form II - Wires and Electric Cables

In this irradiation form II, the electric cable will only be completely irradiated after completing the link. When passing through the electrons beam, it cannot fully penetrate the cable; the irradiation is completed, when the cable passing through the electron beam in position diametrically opposite to the previous one. Taking into account the internal diameter(wire diameter) and the outside diameter(overall cable diameter), after the cable is irradiated at diametrically opposed positions, the dose and the end points and middle of the line tangent to the conductor (greater extension insulator) are equals (Fig. 14).

Examples of irradiation conditions of wires and electric cables in pulley system are shown in Fig. 15. The curve of dose distribution (irradiation form II) is 

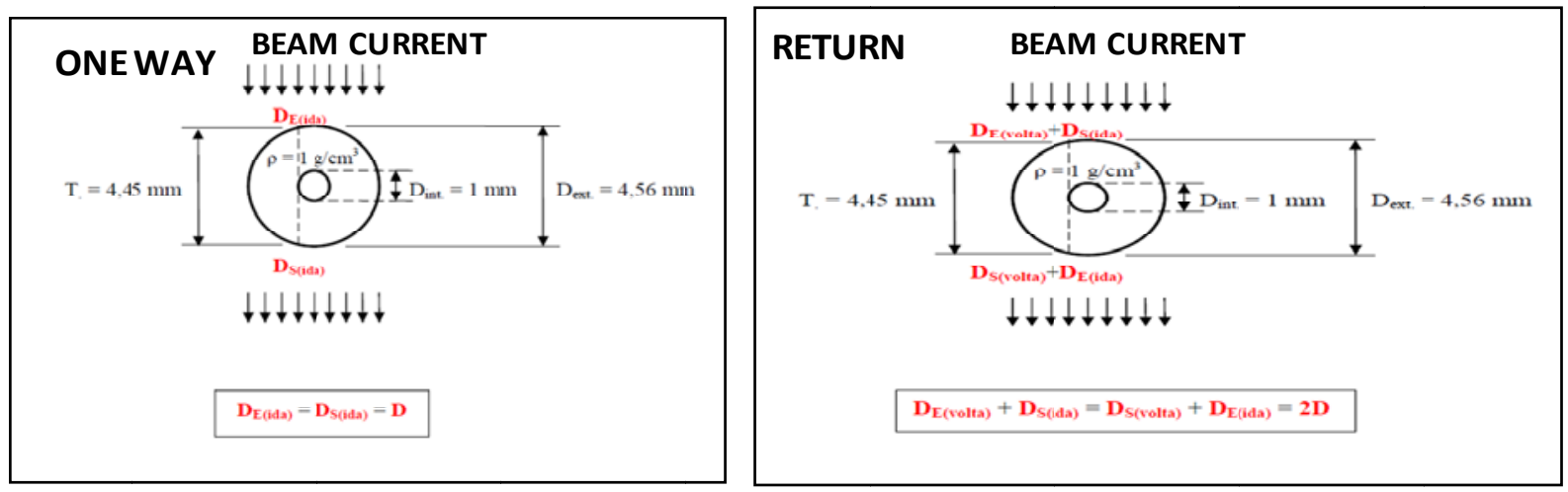

Fig. 12 Irradiation form I - wires and electric cables in pulley system.

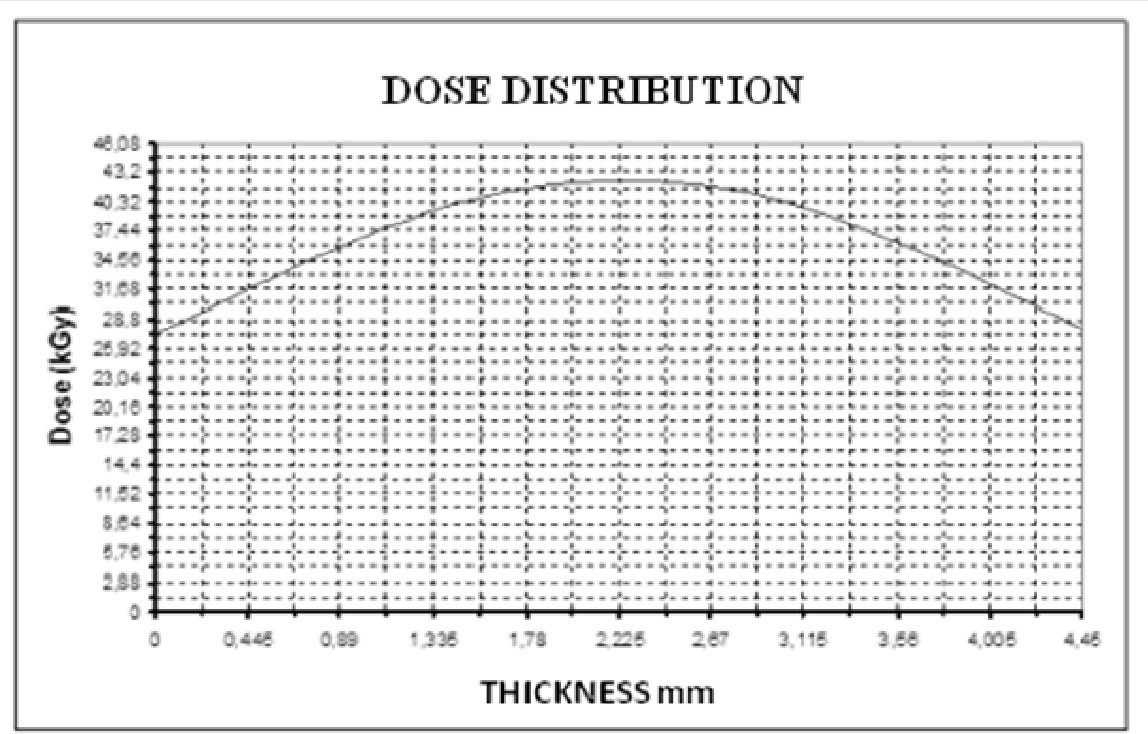

Fig. 13 Curve of distributed dose I - wires and electric cables (kGy/mm).

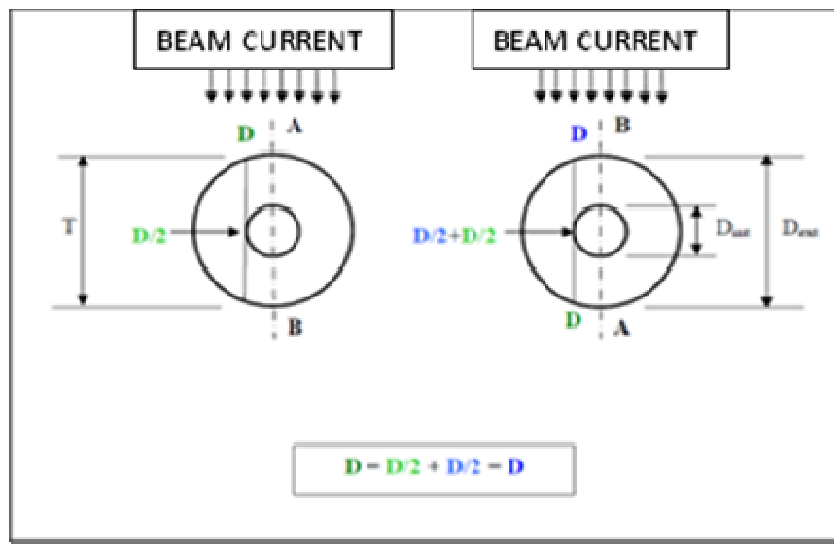

Fig. 14 Irradiation form II - wires and electric cables.

shown in Fig. 16, take into account the following irradiation parameters,

Energy (E) $1.5 \mathrm{MeV}$;
Beam current (I): $10 \mathrm{~mA}$;

Scanning beam: $100 \mathrm{~cm}$;

Speed (v): $100 \mathrm{~m} / \mathrm{min}$;

Number of electron beam passes (P): 48 (24 links);

Total dose (TD): $14.4 \mathrm{kGy}$;

Dose rate (D):40 kGy/s;

Density of the insulating $(\rho): 1 \mathrm{~g} / \mathrm{cm}^{3}$;

Core (internal diameter): $1 \mathrm{~mm}$ (wire diameter);

Outside diameter: $11.34 \mathrm{~mm}$ (overall diameter of the electric cable);

Power beam: $15 \mathrm{~kW}$;

Beam thickness: $25.4 \mathrm{~mm}$ (1").

Take into account the power beam of $15 \mathrm{~kW}$ and beam thickness of $25.4 \mathrm{~mm}(1$ "), dose in their radiated material is calculated by Eq. (3). 

Theoretical Dosimetry for Radiation Processing

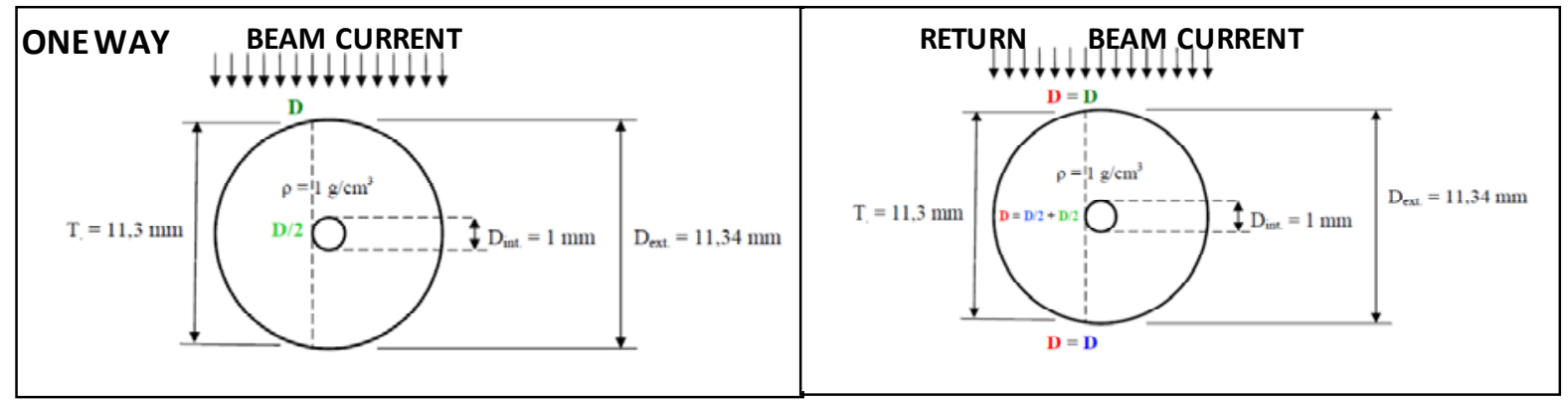

Fig. 15 Irradiation form II - wires and electric cables in pulley system.

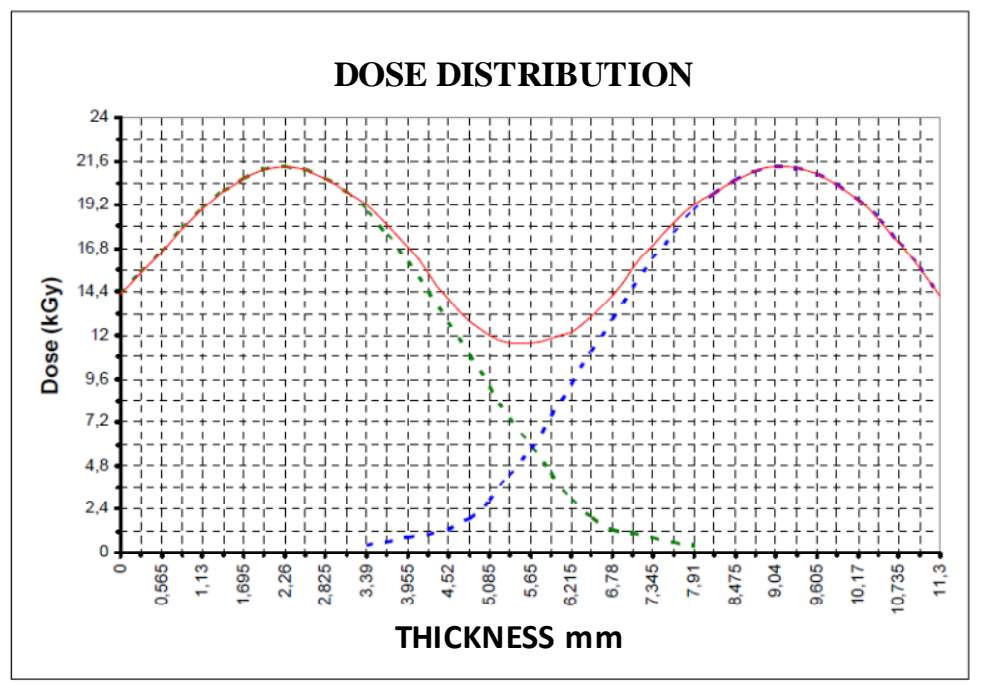

Fig. 16 Curve of distributed dose II -wires and electric cables (kGy/mm).

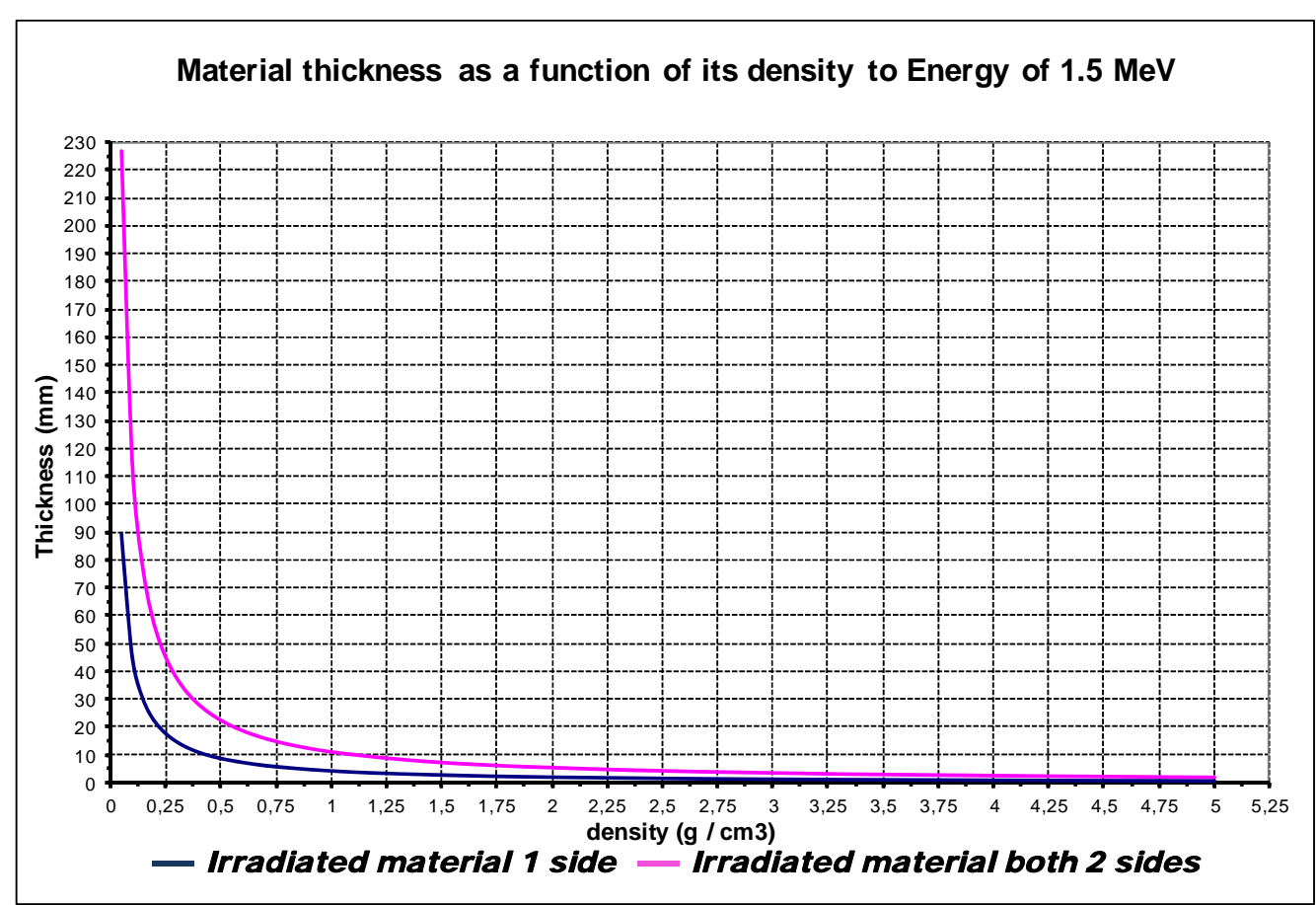

Fig. 17 Graph thickness $(\mathrm{mm})$ versus density $\left(\mathrm{g} / \mathrm{cm}^{3}\right)$ for irradiated materials by Electron Accelerator Dynamitron DC1500/25/4 - JOB 188. 

Theoretical Dosimetry for Radiation Processing
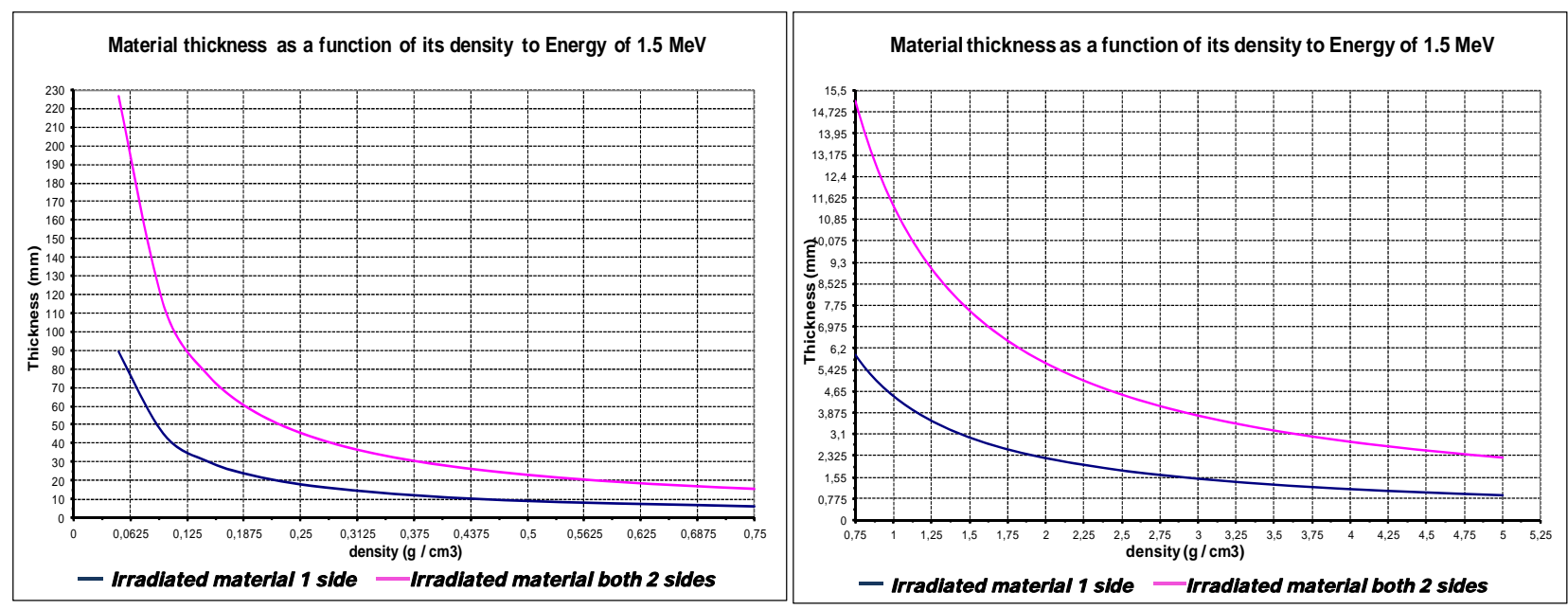

Fig. 18 Graphs with two intervals of density $\left(\mathrm{g} / \mathrm{cm}^{3}\right)$ and material thickness $(\mathrm{mm})$ values.

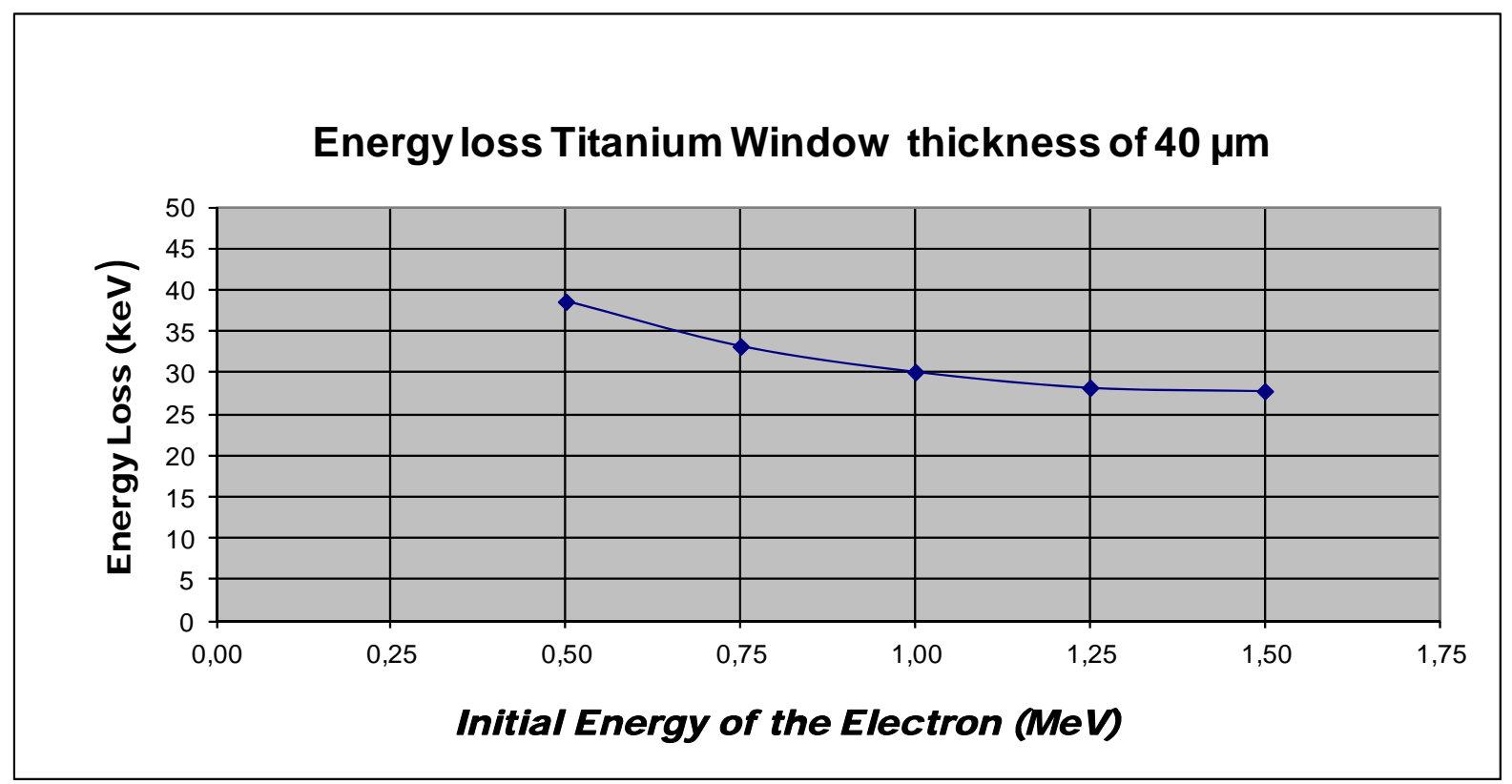

Fig. 20 Curve of energy loss in window (titanium foil).

\section{Thickness of the Material to be Irradiated and} its Density for the Energy of $1.5 \mathrm{Mev}$

The graph (Fig. 17) was obtained using the calculations for determining the conditions of irradiation, for the Electron Accelerator Dynamitron DC1500/25/4- JOB 188.

Fig. 18 is shown the dissociation of the graph thickness $(\mathrm{mm})$ versus density $\left(\mathrm{g} / \mathrm{cm}^{3}\right)$ for irradiated materials in two intervals, with different density values, for better accuracy.

\section{Titanium Window and Energy Loss}

As the high voltage is directly associated with the energy of the electron beam, should we also to be considerate that, in the acceleration process, there are to a loss of energy through the window titanium which isolates the areas in vacuum (the scan horn and beam tube) of the environment with normal atmosphere and by where passes the electron beam. In Fig. 20 is shown the curve of energy loss in window (titanium foil). 


\section{Conclusions}

Through this study, there liability of the equations used in the calculations of their radiation conditions for flat materials and cables could be verified, both for form I and form II of irradiation. These calculations were developed for use in irradiation with the Electron Accelerator Dynamitron DC/1500/25/4 JOB188 at IPEN/CNEN-SP.

Thus, it was concluded:

In the form I of irradiation, using the calculated thickness of $4.45 \mathrm{~mm}$, a small difference between the doses on the upper and on the lower surfaces of the material was found. In the graph, the correct thickness was $4.3 \mathrm{~mm}, 0.15 \mathrm{~mm}$ different from the calculated (approximately 3.37\% less), so that these doses were equal.

In the form of irradiation II, using the calculated thickness of $11.3 \mathrm{~mm}$, a difference between the doses was found, between the dose on the surface of the material and in its middle. The graph shows the correct thickness of $10.7 \mathrm{~mm}, 0.6 \mathrm{~mm}$ different from the calculated (about 5.3\% lower), so that these doses were equal.

This study allows the equivalence between the electrical parameters (beam power), used by industries, and the dose absorbed by the material (kGy) in the electron beam processing. It also explains to researchers the use of the electron irradiation process, the limits of penetration, distribution and dose rates.

\section{References}

[1] International Atomic Energy Agency. 2010. International Irradiation Association. Industrial Electron Beam Processing, IAEA, IIA.

[2] Calvo, W. A. P., Duarte, C. L., Machado, L. D. B., Manzoli, J. E., Geraldo, A. B. C. and Kodama, Y. et al. 2009. "Needs and Emerging Opportunities of Electron Beam Accelerators on Radiation Processing Technology for Industrial and Environmental Applications in South America." International Topical Meeting on Nuclear Research Applications and Utilization of Accelerators IAEA, Vienna, May: 4-8.

[3] Calvo, W. A. P., Duarte, C. L., Machado, L. D. B., Manzoli, J. E., Geraldo, A. B. C. and Kodama, Y. et al. 2012. "Electron Beam Accelerators Trends in Radiation Processing Technology for Industrial and Environmental Applications in Latin America and the Caribbean." Radiation Physics and Chemistry (1993) 81: 1276-81.

[4] Cleland, M. R. and Galloway, R. A. 2009. Electron Beam Crosslinking of Wire and Cable Insulation. Technical Information Series TIS 01812. IBA Industrial, Inc., Edgewood, New York, USA.

[5] Cleland, M. R. 2009. Industrial Applications of Electron Accelerators. IBA Industrial, Inc., Edgewood, New York, USA.

[6] Radiation Dynamics, 1974. Inc. Operation's Instruction Manual for the Dynamitron Electron Accelerator DC1500/25/4, RDI.

[7] Radiation Dynamics, 1994. Inc. General Dynamitron Introductory Manual, RDI.

[8] Radiation Dynamics, 1996. Inc.. Dynamitron Training Course for Electron Beam Accelerator, RDI.

[9] IBA Industrial, 2012. Inc. PLC Dynamitron Training Manual for Electron Accelerator. 